\title{
Research on the Characteristics of Platform Business Incubation Unicorn in the Background of Platform Economy
}

\author{
Pei Ji * \\ School of Management \\ Chengdu University of Information Technology \\ Chengdu, China
}

\author{
Guiqing Li \\ School of Management \\ Chengdu University of Information Technology \\ Chengdu, China
}

\begin{abstract}
With the rapid development of the platform economy, platform enterprises are considered to be the most likely field to incubate unicorns in the future. In order to study the influencing factors of platform enterprises incubating unicorns under the background of the platform economy, this paper analyzes the characteristics of platform enterprises, the environmental influencing factors of platform enterprises incubating unicorns, and the entrepreneurial characteristics of unicorns by means of literature research, deduction and induction, and PEST environmental factor analysis. The research results show that the platform enterprises in the platform economy have the characteristics of cross-network externality, multi-customer, open sharing, unique value, price asymmetry, complexity, demand complementarity and dependence. Platform business incubating unicorns is not only a combination of political, economic, social and technological environments but also related to the high academic background, innovation and entrepreneurship of business leaders. In order to promote the better development of platform enterprises and the emergence of unicorn enterprises, we have proposed management strategies and suggestions from four aspects: business environment, social atmosphere, innovation and entrepreneurship training and establishment of credit system.
\end{abstract}

Keywords-Platform economy; platform enterprise; unicorn enterprise; PEST analysis

\section{INTRODUCTION}

The platform economy is a new type of economy based on modern information technologies such as cloud computing, big data, Internet of things and artificial intelligence, driven by technological innovation and business model innovation. It provides services for supply and demand transactions of multilateral subjects through the Internet platform, so as to obtain benefits and realize efficient allocation of market resources. By the end of 2018, China's Internet penetration rate was $59.6 \%$, the number of Internet users was 829 million, the online retail sales exceeded $¥ 9$ trillion, and the platform’s economic GDP accounted for $10.5 \%$ of GDP. Thus, we have entered the era of the platform economy.

For the study of the platform economy, domestic and foreign scholars mainly focus on the five aspects of "eggborn”, network externality, multi-attribute behavior, platform

Soft Science Project of Science \&Technology Department of Sichuan Province(18 rkx0682); Soft Science Project of Science \&Technology Bureau of Chengdu(2017 - RK00-00047 -ZF); Key Humanities and Social Sciences Projects of Sichuan Education Department(17SA0022) pricing model and market power problem in the bilateral market. The research field involves supermarkets, bank cards, networkIntermediaries, newspapers, magazines, TV media, etc. [1-2]. In the platform economy, there are only two choices for any enterprise. One is to become a platform, the other is to form alliances and exchange values with the platform [3]. The rapid development of platform enterprises has a profound impact on the economic Society, therefore, the platform economy is considered to be a catalyst for the unicorn business incubation. Whether it is a business or an individual, whoever seizes it will take a good future.

\section{OVERVIEW OF THE DEVELOPMENT OF THE PLATFORM ECONOMY}

The platform economy has developed on the basis of the retail e-commerce platform. With the gradual deepening of the integration of the Internet and the industry, the industrial field of the application platform mode increasingly diversified, and the platform has developed from a commercial phenomenon to an economic form [4]. Subsequently, the platform economy was rapidly developed under the impetus of digital globalization and the "Internet+" action plan. It appeared in the form of software application platform, e-commerce platform, financial payment platform and cloud computing service platform, and has become the main production life of people. According to statistics, many large IT and Internet companies at home and abroad are platform enterprises, such as Google, Amazon, Alibaba, Tencent, Baidu, and Jingdong. The world's 15 largest Internet companies are operating in a platform mode, and 60 of the world's 100 largest enterprises have their main revenue mode as well. The platform economy has become the mainstay of the future economy.

\section{PLATFORM ENTERPRISE CHARACTERISTICS}

The platform economy is usually based on resourceconfigured platform enterprises. All resources of these platforms are online, and resources after going online can be mobilized by demanders at any time, thereby reducing search costs and improving the efficiency and success rate of resource integration. In the process of resource allocation, customers can express opinions on the use effect and feelings of products or services, and enterprises can capture such demand information or feedback information at any time to 
adjust the design and optimization of products or services. Therefore, platform enterprises refer more to suppliers as enterprises or consumers, and demanders are consumers, such as Amazon, JD, Taobao, etc. Because of the supply and demand sides, platform companies are also called bilateral enterprises. The cross-network externality of platform enterprises makes the development of the platform more dependent on the participation of the bilateral market entities. From the outside to the inside, the platform enterprises are forced to enhance their openness to form a collaborative development system with bilateral platform participants. Therefore, platform companies have cross-network externalities, multi-customer and open sharing in the bilateral market [5].

In addition, the platform enterprise obtains the value distribution by participating in the process of value realization and value transfer between the buyer and the seller in the transaction, which not only reduces the transaction cost, but also helps the two parties to achieve the transaction efficiently, thus creating and maintaining the market [6]. Platform companies are pricing below the marginal cost of the user, even offering discounts, while the other side is equal to or higher than the marginal cost pricing. If the price structure changes, the platform transaction volume and profit will change. In this complex economy, which emphasizes the value creation within the system, attaches great importance to the needs of all parties and is reasonably satisfied, each group has complementary needs for the platform, and without any party group, the transaction cannot continue. Therefore, platform companies also have unique value, price asymmetry, complexity, demand complementarity and dependence.

\section{PEST ANALYSIS OF PLATFORM BUSINESS INCUBATION UNICORN}

In recent years, the Internet industry has produced the most unicorns in China, and platform companies are seen as the most promising sector to incubate unicorns. In 2017, 36 unicorns emerged from the business split of platform enterprises, accounting for $28.35 \%$ of the number of Chinese unicorn companies. In 2018, there were 202 unicorns in China, and the enterprises with the top 10 valuations belonged to platform enterprises. About 50\% of unicorns are incubated by giant platform enterprises such as Alibaba, JD, Baidu and Tencent. In the context of platform economy, relying on the platform's strong capital accumulation, resource integration and system management capabilities, China's unicorn enterprises are characterized by explosive growth through the platform business splitting or strategic investment [7-8]. In order to explore the reasons why platform enterprises quickly incubate unicorns, this paper will analyze the macro environment from four aspects: politics, economy, society and technology.

\section{A. Political environment}

According to statistics, more than $80 \%$ of unicorn companies originate from high-tech zones. As early as August 2009, the state issued "Several Opinions on Giving Full Play to the Role of National High-tech Industrial Development Zones to Promote Stable and Accelerated Economic
Development", which clearly state that national high-tech zones should give full play to the role of agglomeration, radiation and driving force in leading the development of high-tech industries and supporting local economic growth. Later, with the introduction of "Internet +", innovation-driven strategy, dual-innovation policy, tax preferential policy, and the policy of cultivating unicorns, the scientific and technological power and innovation were pushed to an unprecedented height. The state encourages high-tech talents and enterprises to boldly innovate and start a business. The whole society's innovation and entrepreneurial potential is released, the innovation and entrepreneurship carrier develops rapidly, and social funds focus on innovation and entrepreneurship, creating a good political environment for platform enterprises to incubate unicorns.

\section{B. Economic environment}

In 2018, China's economic growth has progressed steadily, the transformation of new and old kinetic energy has accelerated, corporate investment growth has stabilized, and household consumption has expanded from material to service, from offline to online and offline. The data shows that China's GDP has reached $¥ 900.30$ billion, a year-on-year increase of 6.6\%. High-tech manufacturing, strategic emerging industries and equipment manufacturing industries have increased by $11.7 \%, 8.9 \%$ and $8.1 \%$ respectively over the previous year. The operating income of strategic emerging service industry, technology service industry and high-tech service industry increased by $14.9 \%, 15.0 \%$ and $13.4 \%$ respectively. Investment in high-tech manufacturing and equipment manufacturing increased by $16.1 \%$ and $11.1 \%$ respectively over the previous year. The national online retail sales amounted to $¥ 9006.5$ billion, up $23.9 \%$ over the previous year. Among the per capita consumption expenditure of the national residents, consumer spending contributed $76.2 \%$ to GDP, and service consumption accounts for $44.2 \%$. Economic structure optimization, consumption and demand upgrading, the Internet platform is widely used, platform enterprises effectively gather a large number of stakeholders, meet unlimited demand with unlimited production, reduce costs, and achieve double the growth of income. A stable economic environment allows platform companies to quickly raise funds and more effectively incubate healthy unicorns.

\section{Social environment}

In 2018, the number of Internet users in China was 829 million, and the Internet penetration rate reached $59.6 \%$, of which the mobile Internet users reached 871 million. People use the Internet to conduct business and purchase products on mobile phones has become the norm under the platform economy. The transformation and upgrading of consumption concepts has effectively promoted the development and income generation of platform enterprises. Major universities actively carry out entrepreneurial and innovative education to deliver innovative talents to society. The High-tech Industrial Development Zone actively responds to the national innovation-driven policy, conducts the introduction and training of diverse talents, establishes a talent incentive mechanism, and builds a science and technology demonstration zone to provide local enterprises with the best 
infrastructure, the most complete industrial supporting environment, the most preferential enterprise policies and the most convenient government services. In a favorable social environment, platform companies develop eco-type cooperation with external enterprises, use the convenience of the Internet, collect customer behavior and feedback data to improve management quality, improve the quality of products or services, and achieve win-win cooperation.

\section{Technical environment}

Among the unicorns incubated by platform enterprises in China, e-commerce, Internet finance and other industries all creatively develop their products and services based on the Internet. In recent years, unicorn enterprises are concentrated in the developed areas of manufacturing. In 2018, the manufacturing GDP was ¥264.82 billion, a year-on-year increase of $6.2 \%$. The annual growth of the manufacturing industry has laid a foundation for the growth and development of unicorns. In addition, achievements have been made in the fields of artificial intelligence, big data, cloud computing and other high-tech information technologies. Major breakthroughs have been made in scientific and technological innovation, and scientific and technological achievements have been rapidly industrialized. Beijing, Shanghai and guangzhou have made great efforts to promote the construction of science and technology innovation centers, and major platform companies (Tencent, Alibaba and Huawei) have invested heavily in research and development, providing support for innovation.

\section{ANALYSIS OF THE CHARACTERISTICS OF UNICORN ENTREPRENEURS}

At present, the number of unicorn companies is characterized by explosive growth. The rapid birth of unicorns cannot be separated from the management and decisionmaking of leaders. The basis of personal abilities is closely related to the background of academic qualifications. The study found that unicorn founders were born in a young group of about 30 years old, and were mainly males. More than $90 \%$ of them have a bachelor's degree or above and graduated from well-known universities in China. More than $50 \%$ of the founders are from science and engineering, mainly in computer, communication, electronics, chemical and other fields. Their rich professional knowledge and work experience enable them to have a deep understanding and control over the development of the industry and technological innovation. More than $30 \%$ of the founders majored in financial management, and most of them have taken an MBA/EMBA, so they are very good at corporate management decisions. In addition, most founders have co-founders when they started their business. Before starting a business, they all had entrepreneurial experiences or held key positions in industry leaders. Unicorn entrepreneurs' high academic background and professional knowledge make them attach importance to technological innovation, focus on product development, and lead the team to achieve leapfrog development [9-11]

In addition, unicorn entrepreneurs can lead the company to develop steadily, valuable personality quality is also essential. First is the spirit of innovation, innovation is the primary source of enterprise standing. The founder of Didi taxi, Cheng Wei, takes "making a better trip" as the enterprise tenet, constantly put forward free ride, orange bike and other innovative points, effectively meet the needs of customers and successfully attracted customers. Secondly, change and openness, Starbucks switched to online and offline business under the impact of the Internet economy, which proved that entrepreneurs are adapting to changes in the current situation and constantly adapting their products to market needs in order to get better development. Furthermore, it is a responsibility. Responsibility is greater than the day. Entrepreneurs are honest in making products, courageously taking on the adverse consequences caused by accidents, and ensuring the healthy development of enterprises. Finally, it is the pursuit of excellence, dare to take risks and the courage to take risks. 360 Group founder Zhou Hongyi personally proved that only the constant pursuit of excellence, the courage to take risks, the courage to take risks can lay the cornerstone of the enterprise.

\section{CONCLUSION}

This paper finds that platform enterprises in the context of platform economy have the characteristics of cross-network externality, multi-customer, open sharing, unique value, price asymmetry, complexity, demand complementarity and dependence. The rapid incubation of unicorns by platform companies is inseparable from the interaction of political environment, economic environment, social environment and technological environment. Unicorn entrepreneurs are highly educated, knowledgeable, innovative and sharing, dare to change and take responsibility, dare to take risks and take risks, pursue excellence and other valuable personality qualities. In order to promote the better development of platform enterprises and the emergence of unicorn enterprises, the following countermeasures and suggestions are proposed:

\section{A. Improving the business environment}

At present, the business environment from 78th to 45th world rankings, ranking rose 32-bit, becoming one of the economies with the largest improvement in the business environment. But there is still a low efficiency of construction permit handling, poor tax convenience, the tedious process of starting a business, and the fair competition review system have problems in the central and western regions and economically developed provinces. The business environment restricts the growth of entrepreneurial enterprises. It is necessary to continue to promote the applicability of relevant policies across the country, improve shortcomings and inactions in government duties, reduce the cost of corporate factors and taxes, improve the system of intellectual property, bankruptcy protection of judicial and administrative management system, and eliminate the trouble back at home of entrepreneurs, stimulate innovation power of entrepreneurs.

\section{B. Forming a good social atmosphere for mass innovation and entrepreneurship}

Innovation is the soul of the nation and the theme of the times [12]. The mass innovation and entrepreneurship are the driving force of social development. Reduce the threshold of 
innovation and entrepreneurship, provide rent incentives, technology sharing, entrepreneurship counseling, increase venture capital support and establish a scientific and effective incentive mechanism to stimulate the enthusiasm and potential of the public to innovate and start a business. Vigorously promote entrepreneurial thinking, enhance the orientation of public opinion, let the society pay attention to entrepreneurs, advocate brave entrepreneurship, and dare to be first. Embrace the values of failure and create an atmosphere in which the whole society pays attention to, supports and participates in innovation and entrepreneurship. Strengthen the protection of intellectual property rights for innovative products of start-ups, severely crack down on infringements of innovative intellectual property rights of start-ups, increase illegal costs, and protect the enthusiasm of entrepreneurs for innovation.

\section{Innovating and start training for college students}

Implement the plan for leading college students in starting businesses, provide targeted policy support and services for college students in starting businesses, and strive to expand the scale and increase the proportion of starting businesses. Colleges and universities actively develop and set up special courses, professional counseling and special education for the masses of innovation and entrepreneurship, guiding students to conduct research and exploration in various fields in combination with their entrepreneurial needs and characteristics, and further improve the skills training and innovation and entrepreneurship training and services for college students. Improve the entrepreneurial service system, strengthen tracking and support, strive to improve the success rate of innovation and entrepreneurship, and encourage enterprises to become better, stronger and bigger. The government provides special supporting funds to the school research team and the youth entrepreneurial team builds a business incubator base, actively promotes the technological innovation and achievement transformation of the industryuniversity-research institute. Establish and improve the assessment mechanism for talent training and create a good environment for the talent competition.

\section{Establishing and improve the credit system}

Trust is the core of the development of the sharing economy. A good atmosphere of trust should not only rely on moral constraints, but also be guided by the government to apply the credit system to all aspects of people's lives. At the same time, we must strengthen the punishment of dishonesty and integrate credit into People's Daily life. Establish a new social morality trend of "collaborative sharing" and create a social environment in which entrepreneurs trust each other.

\section{ACKNOWLEDGMENT}

This paper is supported by Soft Science Project of Science \&Technology Department of Sichuan Province(18 rkx0682); Soft Science Project of Science \&Technology Bureau of Chengdu(2017 - RK00-00047 -ZF); Key Humanities and Social Sciences Projects of Sichuan Education Department(17SA0022)

\section{REFERENCES}

[1] Shi Purun, Jiang Keshen.A Study of Monopolistic Airport Pricing Strategy under the Framework of Platform Economics.Management Review,vol.6,pp33-41,2014. (In Chinese).

[2] Iansiti. M, Levein. R.Strategy as Ecology.Harvard Business Review, vol.3,pp.1-10,2004.

[3] Shen Tuo.Different Platforms: Business Model Innovation in the Era of Mobile Internet.Beijing: People's Posts and Telecommunications Press,2012 (In Chinese).

[4] Ye Xiumin.Research on the Role and Mechanism of the Platform Economy to Promote the Innovation of Small and Medium Enterprise.Scientific Management Research,vol.2,pp.62-66,2018.(In Chinese).

[5] Huang Yong, Zhou Xuechun. Research on the Business Model of Platform Enterprises. Commercial Economic, vol.23,pp.23-26,2013.(In Chinese).

[6] Zhao Jixin, Han Kelun.Research on the Influencing Factors and Strategies of Platform-based Internet Corporation Growth. North China Univ of Tech,vol.3,pp.18-24,2018. (In Chinese).

[7] Qin Desheng, Chen Nan. Research on the Factors Affecting the Development of Chinese Unicorn Enterprises. Value Engineering, vol.9,pp184-187,2019. (In Chinese).

[8] Chu Tianjiao, Song Tao.Spatial Distribution and Influence Factors of Unicorn Companies in China.World Regional Studies, vol.6,pp.101109,2017. (In Chinese).

[9] Yuan Xiaohui, Gao Jian.Looking for a Unicorn Company.Tsinghua Management Review,vol.7,pp.28-38,2016. (In Chinese).

[10] Wang Rong. The Enlightenment of the Growth of Unicorn Enterprises in the New Economic Times to Harbin. Management Strategy,vol.21, pp.179-183,2017.(In Chinese).

[11] Che Yunjing. The Source of the "Unicorn" Enterprise Outbreak -- the Entrepreneurial Spirit of the New Era. Leadership Science,vol.11,pp.2729,2018.(In Chinese)

[12] Zhang Ming. Research on Volkswagen Entrepreneurship and Incentive Model of Innovation. Rule of Law and Society,pp.199-200,2017.(In Chinese). 